\title{
Evaluation of Corrosion Behavior of Copper in Chloride Media Using Electrochemical Impedance Spectroscopy (EIS)
}

\author{
A.M. Nagiub* \\ Faculty of Science, Al-Azhar University, Assiut 71524-Egypt
}

Received 13 April 2004; accepted 9 July 2004

\begin{abstract}
The corrosion behavior of pure copper rotating cylinder electrode (RCE) exposed to 3\% $\mathrm{NaCl}$ or artificial seawater prepared as Vätäänen nine salt solution (VNSS) has been studied using electrochemical impedance spectroscopy (EIS) and polarization techniques. EIS experiments for copper RCE were carried out at different rotation rate from $0 \mathrm{rpm}$ to $1600 \mathrm{rpm}$. Polarization resistance $(\mathrm{Rp})$ values were obtained from both EIS and polarization experiments. Excellent agreement between impedance and polarization data is observed. RCE experiments demonstrated that $\mathrm{E}_{\text {corr }}$ and corrosion rate for copper depend linearly on rotation speed $r^{0.7}$. The results obtained showed that EIS is a powerful electrochemical method to follow the change of corrosion mechanisms.
\end{abstract}

Keywords: copper, rotating cylinder electrode, seawater, impedance.

\section{Introduction}

Copper and copper alloys are widely used in many environments and applications due to many factors such as excellent corrosion resistance, superior electrical and thermal conductivity, ease of fabrication and resistance to biofouling. An important use of copper alloys is in handling seawater in ships. The corrosion resistance of copper alloys has been attributed to the formation of a protective film of cuprous oxide $\left(\mathrm{Cu}_{2} \mathrm{O}\right)[1,2]$. Mansfeld et al. studied the effect

\footnotetext{
* Corresponding author. E-mail address: adham_nagiub@yahoo.com
} 
of mass transport, corrosion products and biofilm formation on the corrosion kinetics of different copper alloys exposed to natural and artificial seawater [3]. It was concluded that the increase of corrosion rate of copper alloys with increasing of mass transport at constant $\mathrm{E}_{\mathrm{corr}}$ is due to acceleration of both anodic and cathodic reactions. Y. Feng et al. explained that the increase of corrosion rate is caused by the reduction of the film thickening under rotating condition [4]. There are two possible mechanisms for the observed increase of corrosion rate [5-7]. These are the dissolution-precipitation mechanism and the erosion mechanism.

Using traditional d. c. polarization methods is useful in characterizing the corrosion behavior of metals as well as using a. c. techniques such as EIS. EIS has become a very popular technique in corrosion science. One of the principal advantages of EIS over traditional d. c. techniques is that EIS can be well performed in low solution conductivity, which was a problem that may affect the electrochemical measurements of dc techniques [8-10]. Also EIS is a nondestructive technique (small signal applied during the measurements), so that EIS measurements can be repeated several times using the same electrochemical cell without altering its electrochemical properties. Reviews on the background and applications of EIS have been presented before [8,11-12]. The present work was undertaken to investigate the corrosion behavior of pure copper disk electrode in chloride media using EIS as well as polarization techniques.

\section{Experimental approach}

\section{Material and methods}

Materials: pure copper rotating cylinder electrode (RCE) with exposed area of $1.0 \mathrm{~cm}^{2}$ was prepared by polishing with $\mathrm{SiC}$ paper up to 1200 grit, washing with distilled water and drying in air. The test solution was aerated $3 \% \mathrm{NaCl}$ and artificial seawater (AS) prepared as Vätäänen nine salt solution (VNSS, pH = 7.5) [13] (Table 1). All corrosion measurements have been carried out at room temperature. 
Methods: Two different electrochemical techniques were used to evaluate the corrosion behavior of copper exposed to different solutions.

i- Electrochemical impedance spectroscopy (EIS) was made using an AutoCAD DSP device (ACM Instruments) by applying a sinusoidal voltage signal of 10 $\mathrm{mV}$ over a wide frequency range $\left(10^{4}-10^{-3} \mathrm{~Hz}\right)$. All EIS measurements were made at open circuit potential $\left(\mathrm{E}_{\text {corr }}\right)$ at room temperature.

ii- Electrochemical polarization was obtained using EG\&G 273A potentiostat /galvanostat system. The experiments were run directly after EIS measurements using the same cell used in EIS. A scan rate of $0.2 \mathrm{mV} \mathrm{s}^{-1}$ was used. EIS and polarization measurements were also obtained at various rotation rates from 0 to $1600 \mathrm{rpm}$ in both $\mathrm{NaCl}$ and VNSS solutions. A normal three-electrode configuration (3E) cell was used with saturated calomel electrode (SCE) as a reference electrode. The working electrode in all cases was copper RCE with exposed area of $1 \mathrm{~cm}^{2}$.

Table 1. Composition of VNSS

\begin{tabular}{|c|c|}
\hline Compound & Concentration (g/L) \\
\hline $\mathrm{NaCl}$ & 17.6 \\
\hline $\mathrm{NaHCO}$ & 0.08 \\
\hline $\mathrm{KBr}$ & 0.04 \\
\hline $\mathrm{CaCl}_{2} \cdot 2 \mathrm{H}_{2} \mathrm{O}$ & 0.41 \\
\hline $\mathrm{SrCl}_{2} \cdot 6 \mathrm{H}_{2} \mathrm{O}$ & 0.008 \\
\hline $\mathrm{Na}_{2} \mathrm{SO}_{4}$ & 1.47 \\
\hline $\mathrm{KCl}$ & 0.25 \\
\hline $\mathrm{MgCl}_{2} \cdot 6 \mathrm{H}_{2} \mathrm{O}$ & 1.87 \\
\hline $\mathrm{H}_{3} \mathrm{BO}_{3}$ & 0.008 \\
\hline $\mathrm{FeSO}_{4} \cdot 7 \mathrm{H}_{2} \mathrm{O}$ & 0.01 \\
\hline $\mathrm{Na}_{2} \mathrm{HPO}_{4}$ & 0.01 \\
\hline
\end{tabular}

\section{Results and discussion}

Fig. 1 presents the bode plots obtained for copper RCE exposed to VNSS for 2 weeks under stagnant condition. A diffusion process was observed with a maximum of the phase angle of about $\left(-50^{\circ}\right.$ to $\left.-55^{\circ}\right)$ and $\mathrm{Rp}$ values about $\left(5 \times 10^{3}\right.$ to $\left.10^{4} \mathrm{ohm}\right)$. The appearance of another phase angle not exceeding $45^{\circ}$ at the lowest frequencies is considered to be an indicative of diffusion process $[14,15]$. 
The impedance increased with time, which indicates the improvement of corrosion inhibition with time. A similar effect was observed for copper exposed to $3 \% \mathrm{NaCl}$ solution under stagnant condition (Fig. 2). The impedance spectra shown in both Fig. 1 and Fig. 2 were fitted using the equivalent circuit shown in Fig. 3 (b) [16].
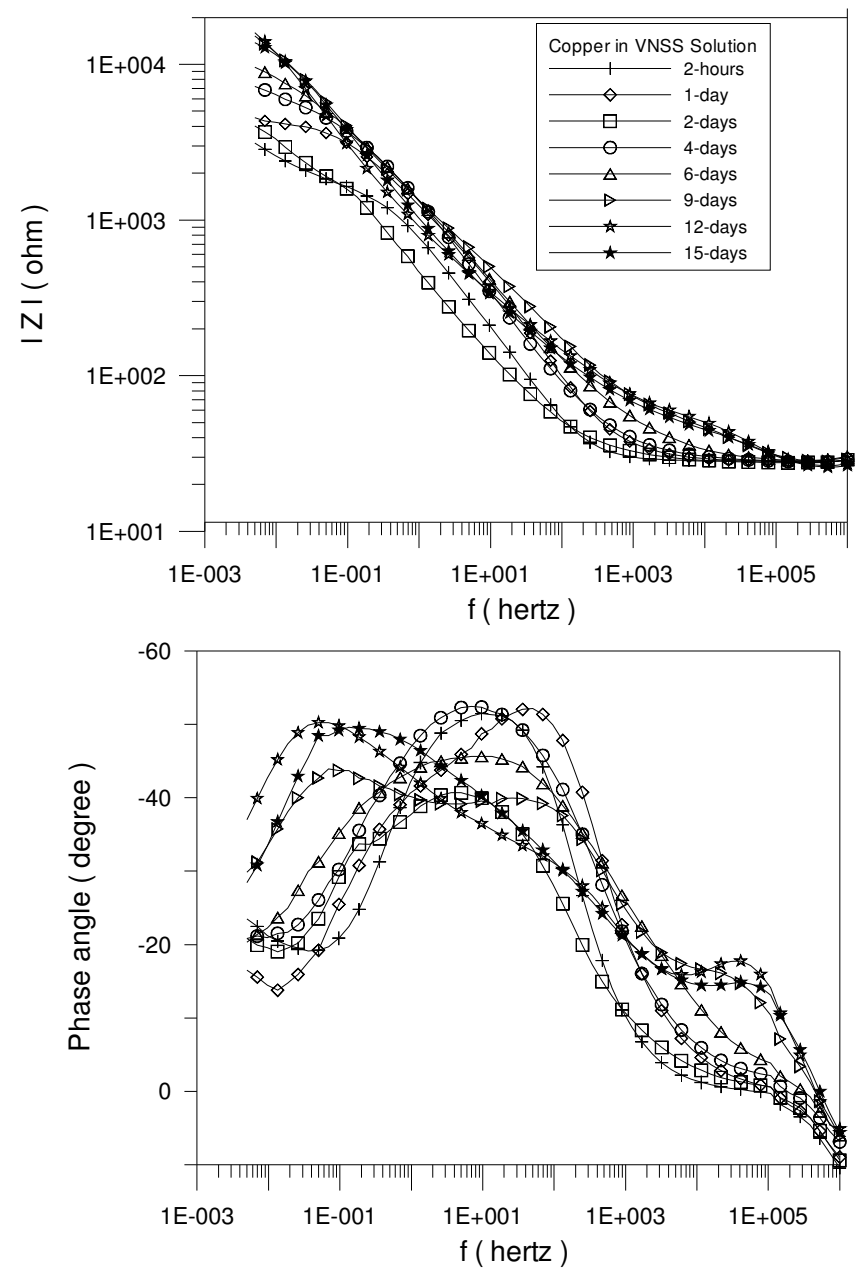

Figure 1. Impedance spectra for copper in VNSS solution.

The impedance spectra for copper have been analyzed using the equivalent circuits (EC) in Fig. 3, where Fig. 3 (a) represents the EC for the one-timeconstant model (OTCM) and Fig. 3 (b) shows the Randless circuit. The elements used in this EC are $C_{d l}, R_{s}, R_{p}$ and $W$. Where $C_{d l}$ is the capacitance of the electrode surface, $\mathrm{Rp}$ is the polarization resistance, $\mathrm{Rs}$ is the solution resistance and $\mathrm{W}$ is the Warburg impedance which is given by: 


$$
\mathrm{W}=[\sigma \omega]^{-1 / 2}(1-\mathrm{j})
$$

where $\mathrm{j}$ is the imaginary number, $\sigma$ is the Warburg coefficient, $\omega=2 \pi \mathrm{f}$ is the angular frequency $(\mathrm{rad} / \mathrm{sec})$, and $\mathrm{f}$ is the frequency. The Randless circuit is used when the corrosion is controlled by a diffusion process with diffusion of reactant and/or products to the interface $[11,17]$.
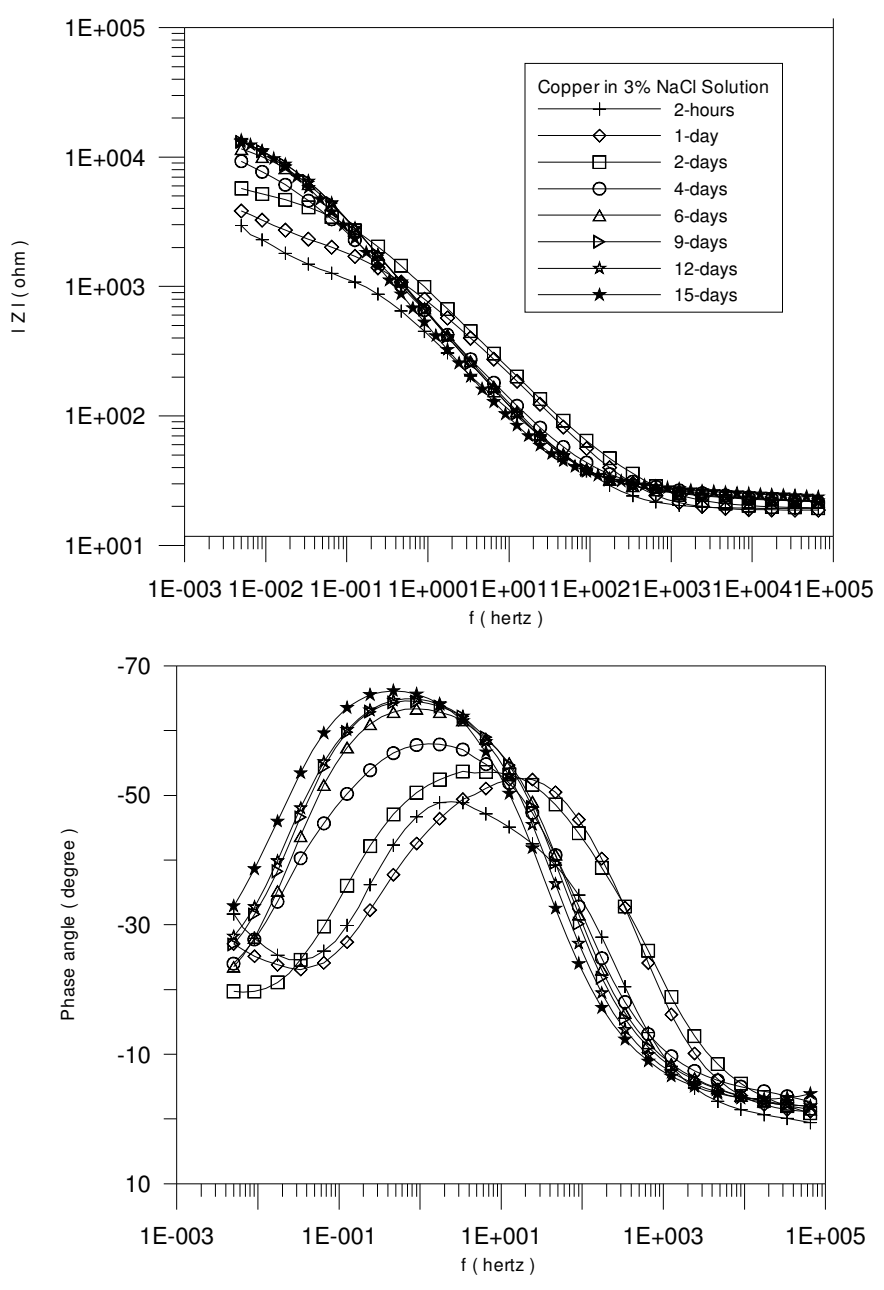

Figure 2. Impedance spectra for copper in 3\% $\mathrm{NaCl}$ solution.

For diffusion controlled process the impedance is given by [18]:

$$
Z_{O}=\left[\tanh B(j \omega)^{1 / 2}\right] / Y_{0}(j \omega)^{1 / 2}
$$

where $\mathrm{B}=l /(\mathrm{D})^{1 / 2}$. $\mathrm{D}$ is the diffusion coefficient, $l$ is the diffusion layer thickness and $Y_{0}=\left(\sigma(2)^{1 / 2}\right)^{-1}$. 


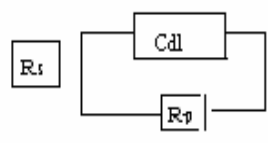

A

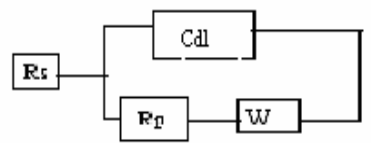

$\mathbf{B}$

Figure 3. Equivalent circuit (EC): (A) one time constant model (OTCM ); Randless circuit.

Fig. 4 shows the experimental and fitted impedance data for copper exposed to $3 \% \mathrm{NaCl}$ for 1 day. The experimental data were fitted using the Randless circuit (Fig. 3 (b)). Excellent agreement between the fitted and experimental data was obtained.

The increase of impedance with time for copper exposed to both $\mathrm{NaCl}$ and VNSS, respectively, is believed to be due to the formation of cuprous oxide. Cuprous oxide then will further oxidize to cupric hydroxychloride atacamite [3]. The results shown in both Fig.1 and 2 suggest that the increase of impedance with immersion time may be due to the thickening of the oxide film [4].

Fig. 5 and 6 show the effect of rotation rate on the bode plots for copper exposed to $\mathrm{NaCl}$ after 1 and 4 days, respectively. Bode plot for copper exposed to stagnant $\mathrm{NaCl}$ solution $(\mathrm{r}=0)$ is characterized by the appearance of a phase angle minimum at low frequencies. This minimum phase angle is disappeared with increasing of rotation rate. It can be concluded that EIS plots were changed from a pure diffusion control process (when $\mathrm{rpm}=0$ ) to simply a one time constant model (OTCM) with increasing the rotation rate of the copper disk electrode. Accordingly, these results indicate that corrosion mechanism was changed from a diffusion-controlled process mechanism to simply uniform corrosion attack mechanism. Fig. 7 shows the experimental and fitted impedance data for copper 
RCE (r=200) exposed to $3 \% \mathrm{NaCl}$ for 1 day. Good agreement between the fitted and experimental data was obtained.
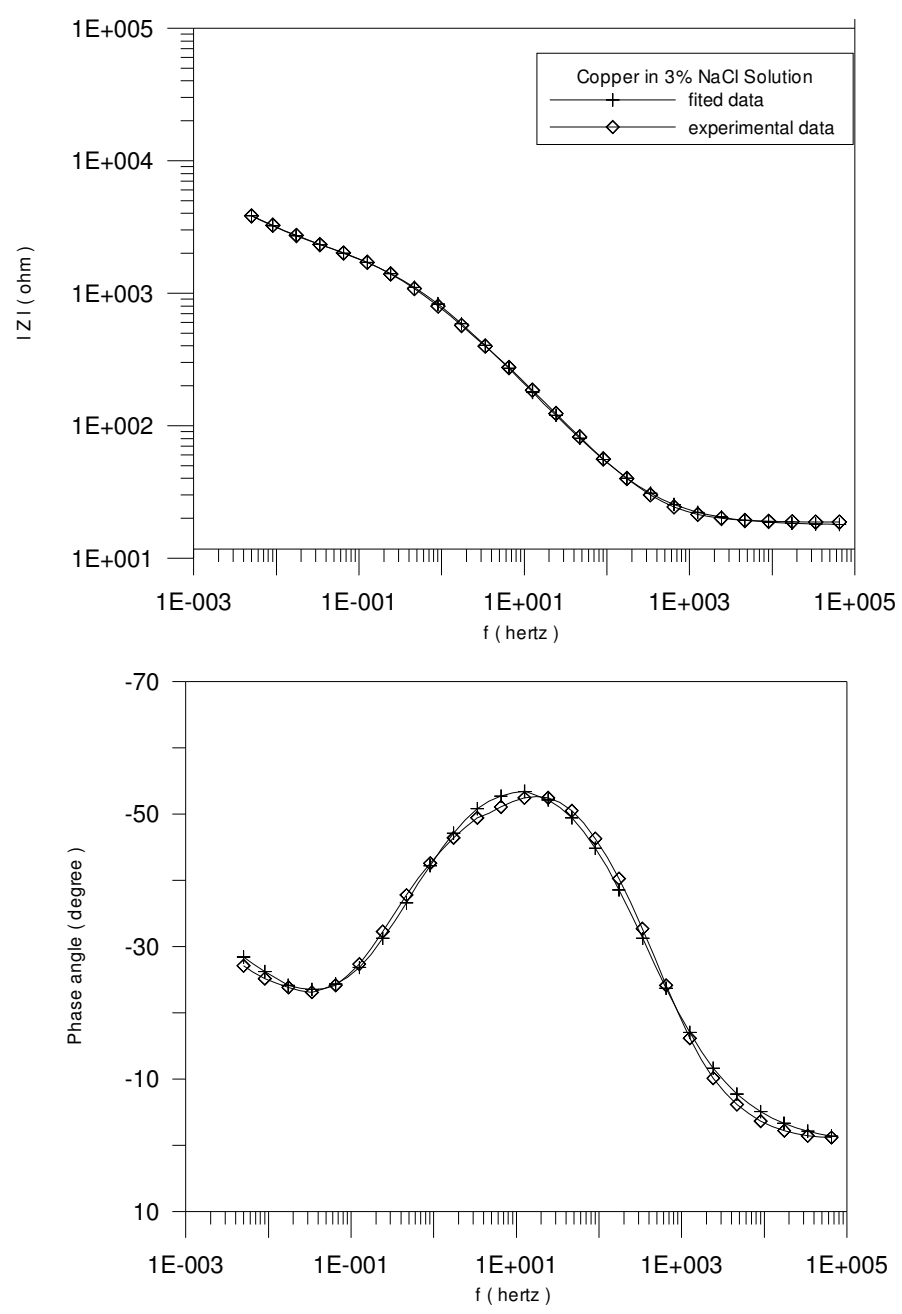

Figure 4. Comparison of experimental and fit data for copper exposed to $3 \% \mathrm{NaCl}$ solution after 1 day.

Corrosion of fresh pure copper electrode exposed to seawater is believed to occur according to the following reaction [19]:

$$
\begin{array}{cc}
\text { anodic reaction } & \mathrm{Cu} \rightarrow \mathrm{Cu}^{+}+\mathrm{e}^{-} \\
\text {cathodic reaction } & \mathrm{O}_{2}+2 \mathrm{H}_{2} \mathrm{O}+4 \mathrm{e}^{-} \rightarrow 4 \mathrm{OH}^{-}
\end{array}
$$

followed by the formation of cuprous complex, 


$$
\mathrm{Cu}^{+}+2 \mathrm{Cl}^{-} \rightarrow \mathrm{CuCl}_{2}^{-}
$$
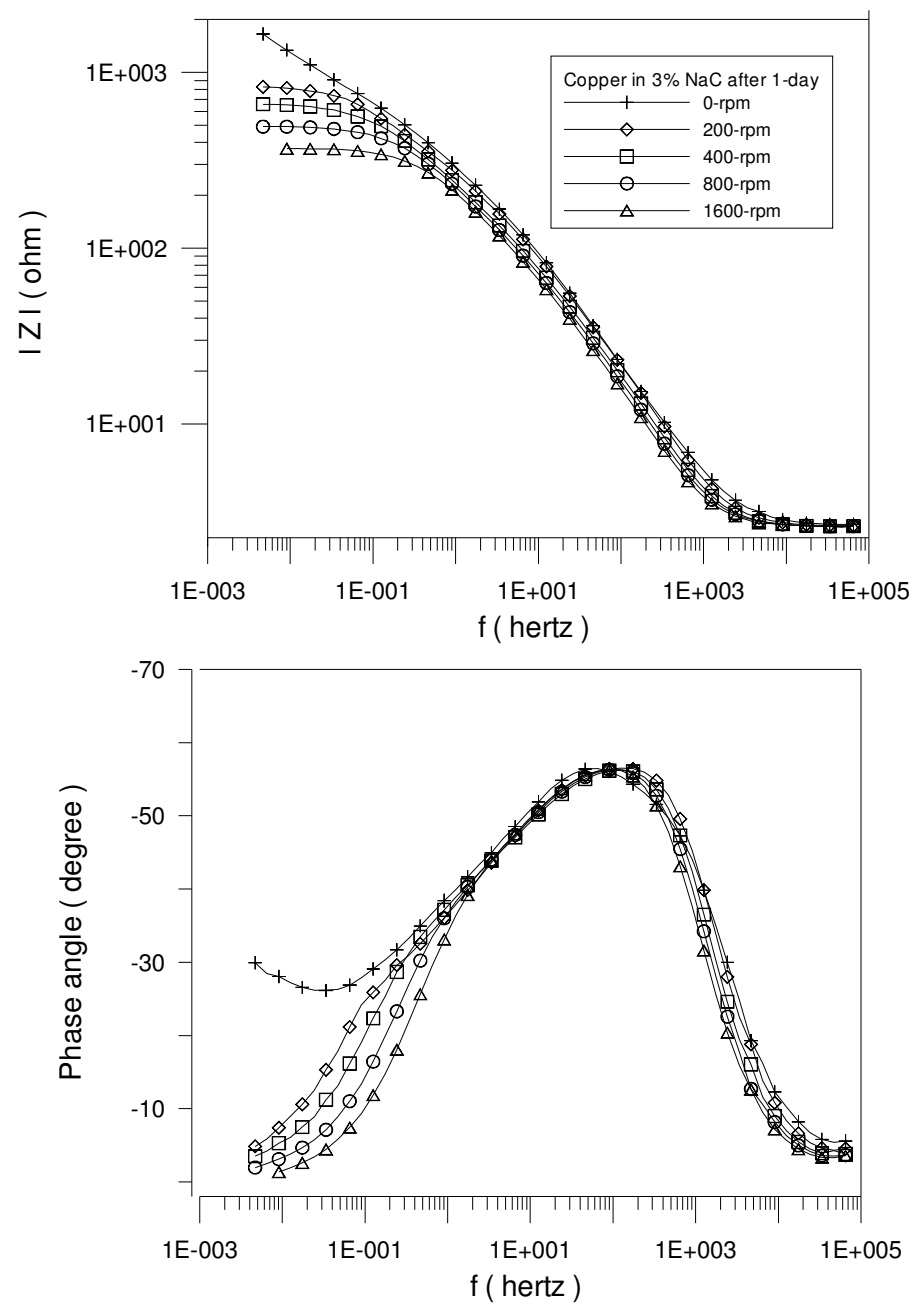

Figure 5. Dependence of impedance spectra on rotation rate for copper in $3 \% \mathrm{NaCl}$ solution after 1 day.

then cuprous oxide will be formed as:

$$
2 \mathrm{CuCl}_{2}^{-}+2 \mathrm{OH}^{-} \rightarrow \mathrm{Cu}_{2} \mathrm{O}+\mathrm{H}_{2} \mathrm{O}+4 \mathrm{Cl}^{-}
$$

Finally, the formation of cupric hydroxychloride atacamite, which is less protective:

$$
\mathrm{Cu}_{2}+1 / 2 \mathrm{O}_{2}+\mathrm{Cl}^{-}+\mathrm{H}_{2} \mathrm{O} \rightarrow \mathrm{Cu}_{2}(\mathrm{OH})_{3} \mathrm{Cl}+\mathrm{OH}^{-}
$$



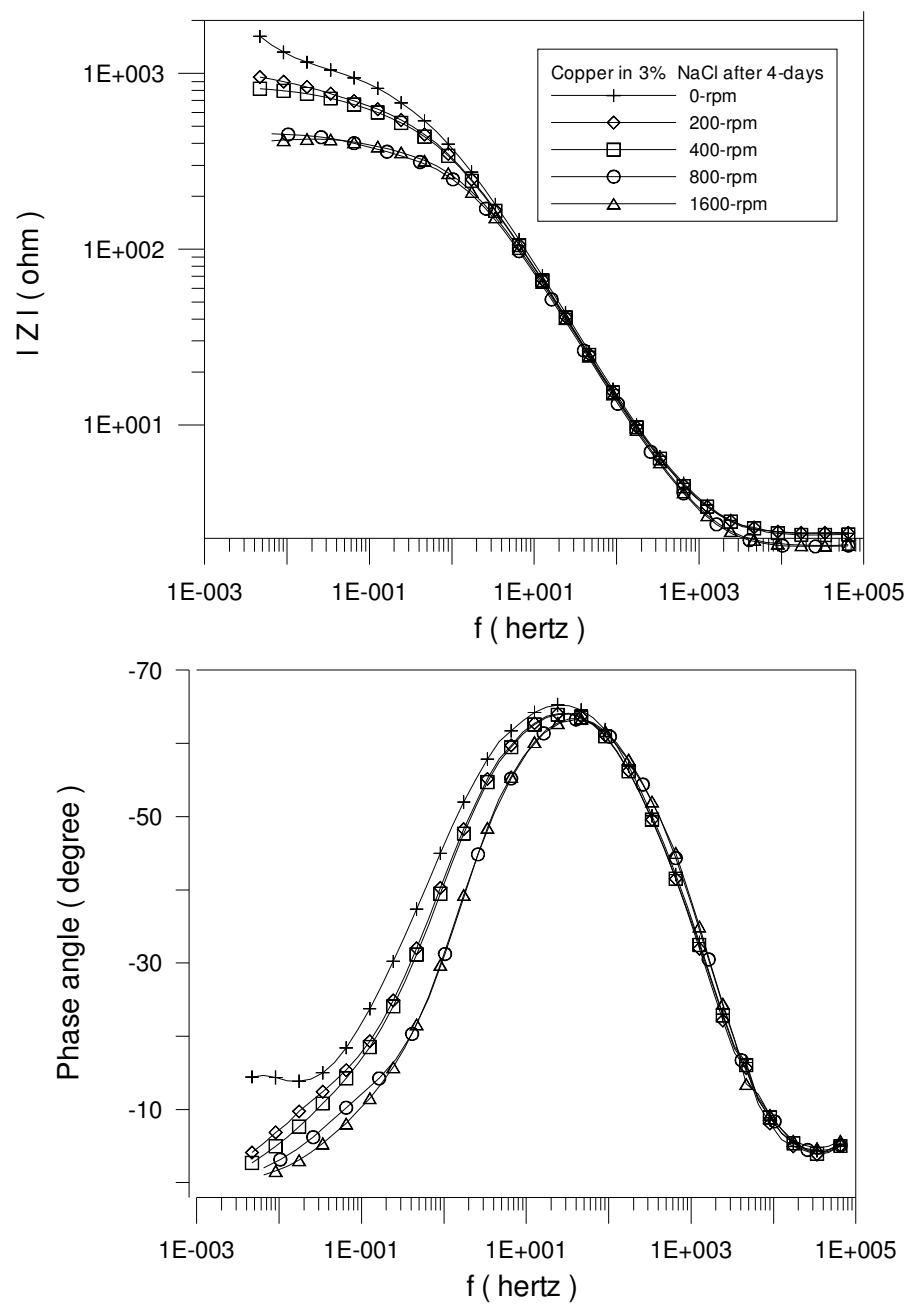

Figure 6. Dependence of impedance spectra on rotation rate for copper in $3 \% \mathrm{NaCl}$ solution after 4 days.

According to the above equations, the movement of $\mathrm{O}_{2}, \mathrm{OH}^{-}, \mathrm{Cu}^{+}$and $\mathrm{CuCl}_{2}{ }^{-}$to and from the corroding surfaces will control the corrosion of copper. According to mixed potential theory, increased transport of $\mathrm{Cl}^{-}$or $\mathrm{CuCl}_{2}$, to or from the surface, will accelerate the anodic reaction, while the increase of $\mathrm{O}_{2}$ transport will increase the cathodic reaction, so that the corrosion rate will increase. To clarify these results Tafel polarization curves were obtained for copper RCE exposed to $3 \% \mathrm{NaCl}$ at different rotation rates (Fig. 8). 

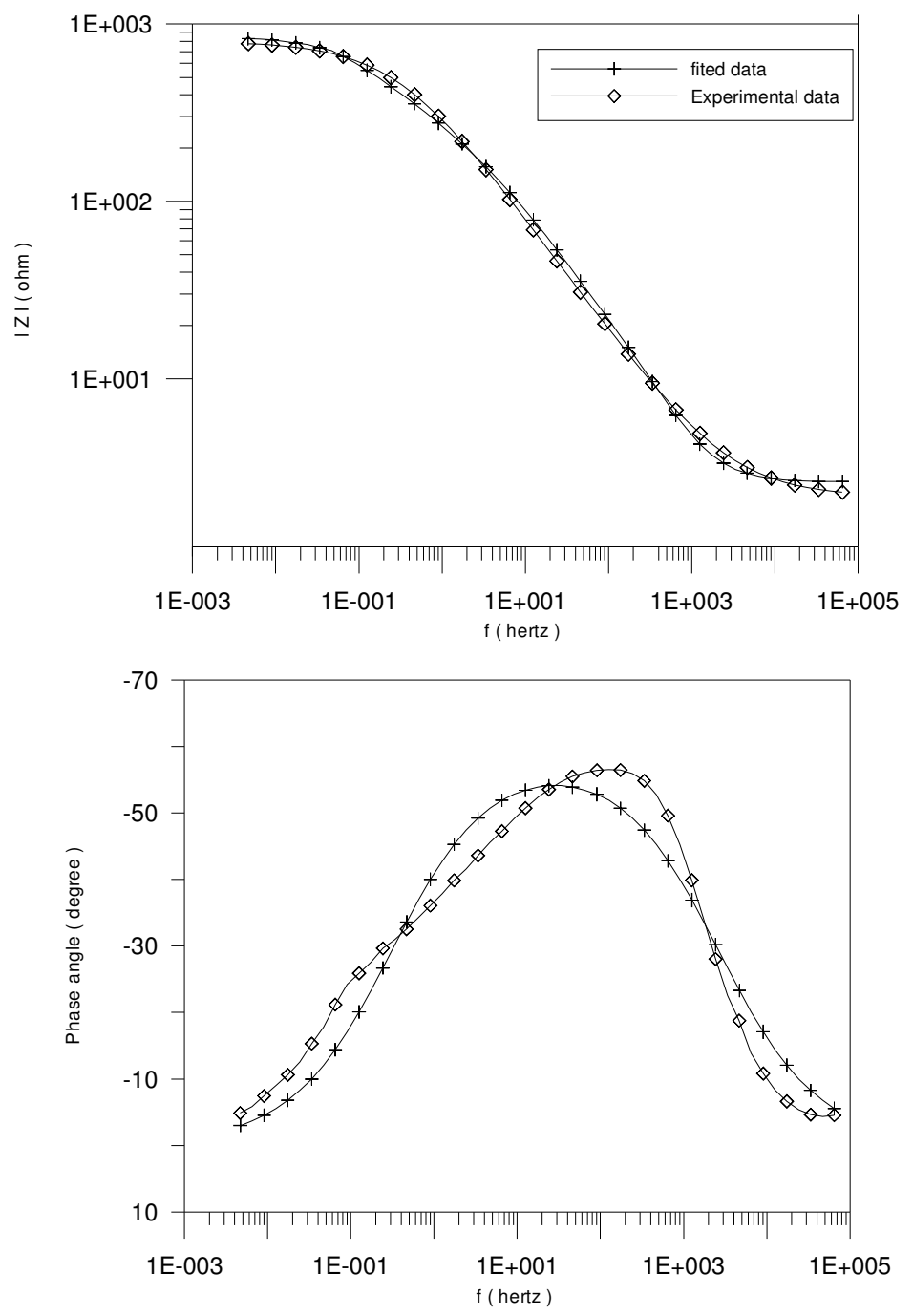

Figure 7. Comparison of experimental and fit data for copper RCE $(r=200)$ exposed to $3 \% \mathrm{NaCl}$ solution after 1 day.

From Fig. 8 it is clear that the anodic current density curves were shifted to higher values as a result of increasing rotation rates while cathodic current curves remained nearly unchanged under rotating conditions. This behavior could be due to the decrease of the oxide film thickness under rotating condition [4]. There are two possible mechanisms describing the reduction of film thickness of copper and its alloys in seawater: the dissolution-precipitation mechanism and the erosion mechanism [5-7]. From both mechanisms, it was concluded that a film will grow over the corroding surface if the binding force between the film and the substrates is greater than the shear force. Accordingly, under rotating 
conditions the oxide particles are washed from the surface into the solution due to the action of hydrodynamic shear force.

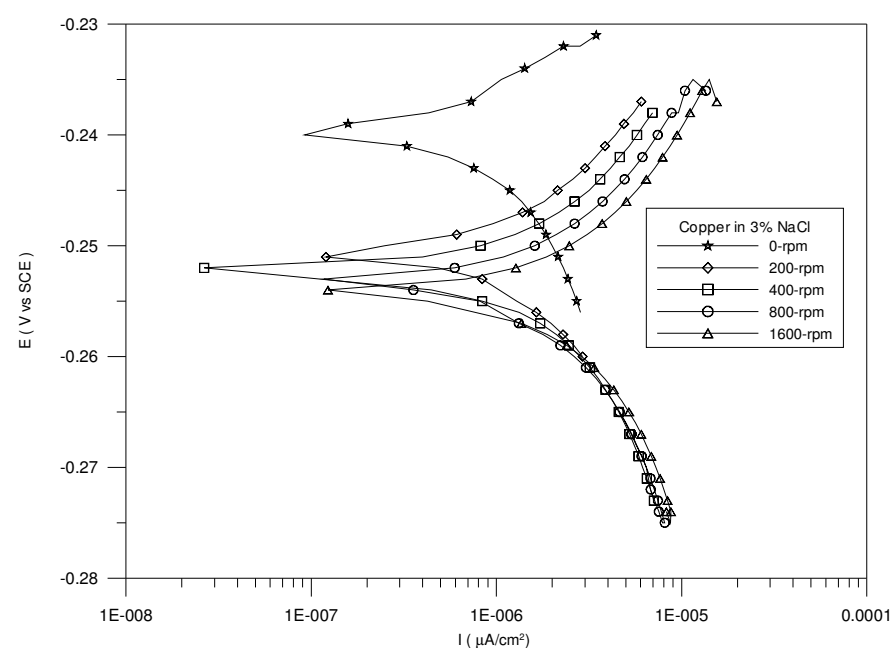

Figure 8. Polarization curves for copper exposed to $3 \% \mathrm{NaCl}$ for 1 day at different rotation rates.

The results shown in Fig. 8 agree with earlier findings by Mansfeld and Kenkel [20], showing that the anodic polarization curve will be shifted to higher current density with increasing of r. Fig. 9 shows the dependence of $\mathrm{E}_{\text {corr }}$ for copper $\mathrm{RCE}$ exposed to $3 \% \mathrm{NaCl}$ for 4 days, on rotation rates $\left(\mathrm{r}^{0.7}\right)$ where the exponent 0.7 is appropriate for rotating cylinder electrode measurements [21]. A small negative shift (about $5 \mathrm{mV}$ ) of $\mathrm{E}_{\text {corr }}$ was observed with increasing $\mathrm{r}$.

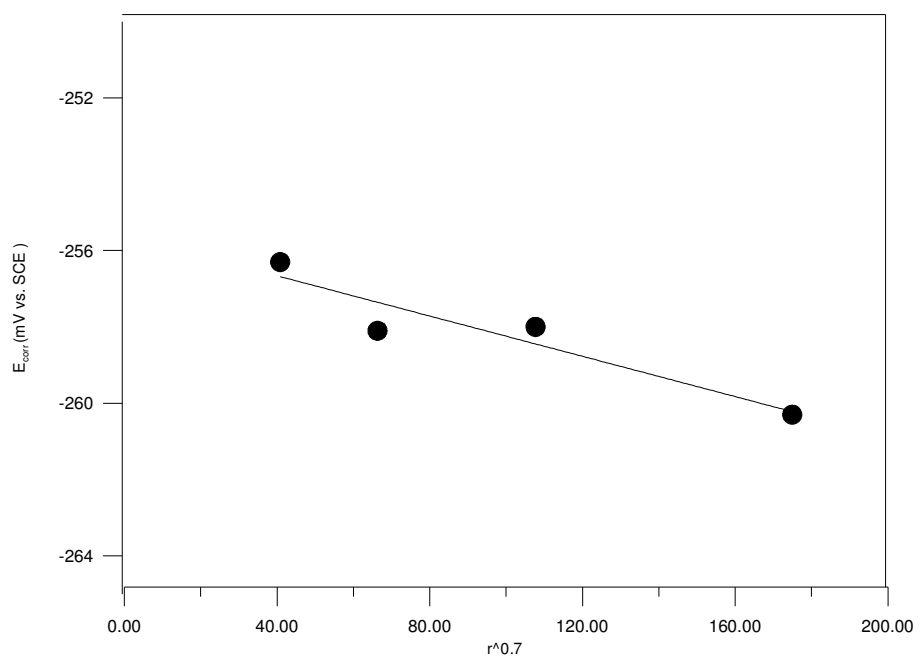

Figure 9. The dependence of $\mathrm{E}_{\mathrm{corr}}$ on $\mathrm{r}^{0.7}$ for copper RCE exposed to $\mathrm{NaCl}$ for 4 days. 
Fig. 10 shows the dependence of $1 / R_{p}$ on the rotation rate for copper RCE exposed to $3 \% \mathrm{NaCl}$ for 4 days. $\mathrm{R}_{\mathrm{p}}$ values were calculated from EIS and polarization measurements. A very good agreement between Rp values calculated from EIS and polarization techniques was obtained. Contrary to $E_{\text {corr }}, 1 / R_{p}$ increased with the increasing of rotation rate. Increase of $1 / R_{p}$ means that the corrosion rate will increase with the increasing of rotation rate.

According to the data shown in Fig. 9 and 10 the dependence of $E_{\text {corr }}$ and $1 / R p$ can be expressed as:

$$
\begin{aligned}
& E_{\text {corr }}=a+a^{\prime \prime} r^{0.7} \\
& 1 / R_{p}=b+b^{\prime \prime} r^{0.7}
\end{aligned}
$$

where $\mathrm{a}$ and $\mathrm{b}$ are the values of $\mathrm{E}_{\text {corr }}$ and $1 / \mathrm{R}_{\mathrm{p}}$, respectively, at stagnant condition, and $\mathrm{a}^{\prime \prime}$ and $\mathrm{b}^{\prime \prime}$ are regression slopes, respectively. $\mathrm{E}_{\text {corr }}$ was not significantly changed with $r$, while $b^{\prime \prime}$ is a positive value indicating that corrosion rates increased with increasing $\mathrm{r}$ (Fig. 9 and 10)). By extrapolating the regression line according to equations (8) and (9) to $\mathrm{r}=0$, parameters $\mathrm{a}, \mathrm{b}, \mathrm{a}$ " and $\mathrm{b}$ " can be determined.

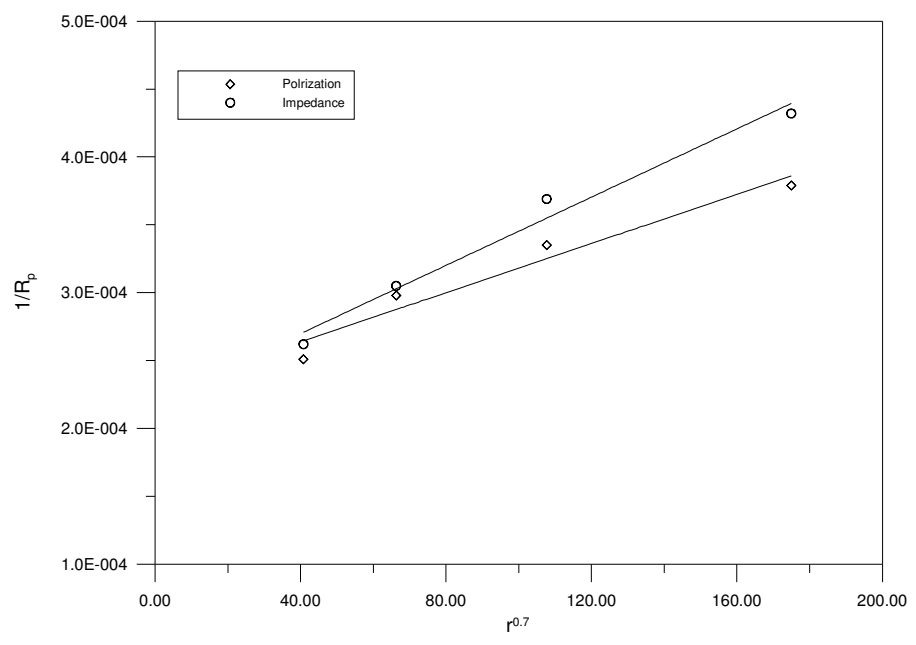

Figure 10. The dependence of $1 / \mathrm{R}_{\mathrm{p}}$ on $\mathrm{r}^{0.7}$ for copper RCE expsoed to $\mathrm{NaCl}$ for 4 days. 


\section{Conclusions}

The effect of rotation rate on the corrosion behavior of copper disk electrode demonstrated that mass transport significantly affect the corrosion behavior of copper exposed to both $\mathrm{NaCl}$ and VNSS solutions. Nearly identical bode plots were obtained for copper RCE exposed to VNSS and to $3 \% \mathrm{NaCl}$. It was concluded that the corrosion mechanism for copper RCE is the same in both media. The results of this work also demonstrated that EIS is a powerful technique to follow the change in corrosion mechanisms from stagnant system ( $\mathrm{r}$ $=0)$ condition to flow system as indicated by the disappearance of the second time constant at the lowest frequency in the impedance plot. The obtained Rp values were nearly similar to $\mathrm{Rp}$ values obtained from polarization techniques, which will prove that the EIS fitting models used in this study were successfully chosen to describe the corroding system. Polarization data showed that anodic current density was shifted to higher values with the increasing of rotation rates, which is in agreement with the observed decrease of the impedance.

\section{References}

1. R. North, M.J. Pryor, Corros. Sci. 10 (1970) 297.

2. R.G. Blundy, M.J. Pryor, Corros. Sci. 12 (1972) 65.

3. F. Mansfeld, G. Liu, H. Xiao, C.H. Tsai, J. Little, Corros. Sci. 36 (1994) 2063.

4. Y. Feng, W.K. Teo, K.S. Siow, K.L. Tan, A.K. Hsieh, Corros. Sci. 38 (1996) 369.

5. B.J. Miller, Electrochem. Soc. 116 (1969) 1675.

6. V. Ashworth, D. Fairhurst, J. Electrochem. Soc. 124 (1977) 1675.

7. S.K.D. Efird, Corrosion 33 (1977) 1.

8. F. Mansfeld, W.J. Lorenz, in " Techniques for Characterization of Electrodes and Electrode Process", edited by R. Varma and J.R. Selman, John Wiley, (1991) 581-647. 
9. F. Mansfeld, M.W. Kendig, Proc. Eur. Symp. Corros. Inhibitors, (1985) $6^{\text {th }}$ Ferrara, Italy.

10. F. Mansfeld, M.W. Kendig, S. Tsai, Corros. Sci. 22 (1982) 455.

11. D.D. MacDonald, "Impedance Spectroscopy”, (1987) John Wiley.

12. D.D. MacDonald, Corrosion 46 (1990) 229.

13. G. Hernandez, V. Kucera, D. Thierry, A. Pedersen, M. Hermansson, Corros. Sci. 50 (1994) 603.

14. A.M. Fenelon, C.B.J. Breslin, Appl. Electrochem. 31 (2001) 509.

15. F. El-Taib Heakal, S. Haruyama, Corros. Sci. 20 (1980) 887.

16. A. Nagiub, F. Mansfeld, Corros. Sci. 43 (2001) 2147.

17. F. Mansfeld, C.H. Tsai, H. Shih, ASTM STP 1154, American Society for Testing and Materials, Phyladelphia, 1992, p. 186.

18. F. Mansfeld, L.T. Han, C.C. Lee, G. Zhang, Electrochim. Acta 43 (1998) 2933.

19. G. Bianchi, G. Fiori, P. Longhi, F. Mazza, Corrosion 34 (1978) 396.

20. F. Mansfeld, J.V. Kenkel, Corrosion 33 (1977) 376.

21. J. Gabe, Appl. Electrochem. 4 (1974) 91. 